\begin{tabular}{|c|l|}
\hline Title & Influence of silicon on the growth of barrier-type anodic films on titanium \\
\hline Author(s) & Tanvir, M. Tauseef; Fushimi, K.; Shimizu, K.; Nagata, S.; Skeldon, P.; Thompson, G.E.; Habazaki, H. \\
\hline Citation & $\begin{array}{l}\text { Electrochimica A cta, 52(24), 68346840 } \\
\text { https://doi.org/10.1016/.electacta.2007.04.113 }\end{array}$ \\
\hline Issue Date & 2007-08-01 \\
\hline Doc URL & http://hdl.handle.net/2115/27971 \\
\hline Type & article (author version) \\
\hline File Information & ECA52-24.pdf \\
\hline
\end{tabular}

Instructions for use 


\section{Influence of Silicon on the Growth of Barrier-Type Anodic Films on Titanium}

M. Tauseef Tanvir*, K. Fushimi*, K. Shimizu**, S. Nagata ${ }^{\dagger}$, P. Skeldon*, G.E. Thompson ${ }^{*}$ and H. Habazaki*, a

*Graduate School of Engineering, Hokkaido University, N13-W8, Sapporo 060-8628, Japan

**University Chemical Laboratory, Keio University, 4-1-1, Hiyoshi, Yokohama 223-8521, Japan

${ }^{\dagger}$ Institute for Materials Research, Tohoku University, 2-1-1, Katahira, Sendai 980-8577, Japan "Corrosion and Protection Centre, School of Materials, The University of Manchester, P.O. Box 88, Manchester M60 1QD, UK

${ }^{a}$ Corresponding author: phone\&fax: +81-11-706-6575; e-mail: habazaki@eng.hokudai.ac.jp 
Abstract

Amorphous anodic titania, stabilised by incorporation of silicon species, is shown to grow to high voltages on sputter-deposited, single-phase Ti-Si alloys during anodizing at a constant current density in ammonium pentaborate electrolyte. The films comprise two main layers, with silicon species confined to the inner layers. An amorphous-to-crystalline transition occurs at $\sim 60 \mathrm{~V}$ on the Ti- 6 at $\% \mathrm{Si}$ alloy, while the transition is suppressed to voltages above $140 \mathrm{~V}$ on alloys with 12 and 26 at\% silicon. The crystalline oxide, nucleated at a depth of $\sim 40 \%$ of the film thickness, is associated with the presence of a precursor of crystalline oxide in the pre-existing air-formed oxide. The modified structure of the air-formed oxide due to increased incorporation of silicon species suppresses the amorphous-to-crystalline transition until the onset of dielectric breakdown. The transport numbers of cations and anions during growth of the anodic oxides are independent of the concentration of silicon species in the inner layer, despite the marked change in the field strength.

Keywords: anodic oxide, ionic transport, anodic titania, amorphous-to-crystalline transition 


\section{Introduction}

Anodic titanium oxide has attracted much attention due to its potential widespread applications, including photocatalysis, photovoltaics, sensors and capacitors [1]. Such interest in the anodic titanium oxide has been enhanced by the recent development of self-organized porous anodic titanium nanotubes in fluoride-containing electrolytes [2, 3]. For capacitor applications in the microelectronics industry, a dense and flaw-free barrier oxide must be formed as a dielectric layer. In contrast to anodic aluminium oxide $\left(\varepsilon_{\mathrm{ox}}=10\right)$ and tantalum oxide $\left(\varepsilon_{\mathrm{ox}}=27\right)$, which are currently used in commercial electrolytic capacitors, anodic oxide films develop with a high population density of flaws on high purity titanium in aqueous electrolytes. Thus, anodic titanium oxide-based capacitors have not been realized practically despite the large permittivity of the oxide [4].

The development of flaws in anodic titanium oxide is associated with crystallisation of the anodic oxide during anodizing. Initially, the anodic film is amorphous, but an amorphous-to-crystalline transition occurs at voltages of less than $10 \mathrm{~V}$ [4]. The crystalline oxide in the film provides an electron-conducting path, which enables oxygen generation to occur on crystalline regions [5]. From transmission electron microscopy (TEM) of ultramicrotomed sections, the crystalline oxide is formed in the inner part of the films, where the film material is developed at the metal/film interface [6]. The crystalline oxide develops further during thickening of the anodic film, being evident from the increased size of crystalline regions with increasing distance from the metal/film interface. Gas bubbles generated at the crystalline regions in the anodic films are directly observed by TEM, and increased gas pressure in the bubbles with film growth results in the breakdown of the anodic film. The previous findings suggest that crystalline oxide is nucleated when the titanium oxide is developed at the metal/film interface, while the film material in the outer region, formed at the film/electrolyte interface, is only amorphous. 
It is well known that crystallisation of amorphous anodic oxides is impeded by incorporation of foreign species. For instance, electron beam-induced crystallisation of anodic alumina during TEM observation is delayed in the outer film regions containing electrolyte-derived species [7]. For anodic titanium oxide, effective suppression of crystallisation has been demonstrated by incorporation of silicon species from the metal substrate, i.e., anodizing of a Ti-6 at $\%$ Si alloy $[6,8,9]$. Alloying of titanium with other metals, such as aluminium, molybdenum, niobium, tungsten and zirconium, is also effective, although higher concentrations of alloying elements, compared with silicon addition, are required to form amorphous oxide without crystallisation to voltages higher than $100 \mathrm{~V}[10]$.

Even for the Ti- 6 at $\%$ Si alloy, crystalline oxide is formed at increased voltages, but the crystals are nucleated only at a depth of $\sim 40 \%$ of the film thickness [6]. Since the transport number of cations in the growing anodic oxide is approximately $0.4[8,9]$, the depth of the crystals corresponds to the boundary between film material developed by outward migration of cations and inward migration of anions. In general, amorphous anodic oxide grows due to simultaneous migration of outwardly mobile cations and inwardly mobile anions through a pre-existing air-formed oxide. The development of crystalline oxide only at the marker plane suggests that its nucleation is associated with the air-formed oxide; no crystals are nucleated when the oxide is developed at the alloy/film interface. In fact, an influence of ageing of the air-formed oxide on crystallisation of anodic oxide has been reported [6].

In this work, for a further understanding of the amorphous-to-crystalline transition of the anodic oxide, the influence of silicon content in Ti-Si alloys on the growth and crystallization of the anodic oxide has been examined using TEM, Rutherford backscattering spectroscopy (RBS) and X-ray photoelectron spectroscopy (XPS). The dielectric properties of the resultant anodic oxides have also been examined by impedance spectroscopy. 


\section{Experimental}

Ti-Si alloy films, containing 6, 12 and 26 at\% silicon, as well as 99.9\% pure titanium, were prepared by dc magnetron sputtering on to glass plates and aluminium sheets. The aluminium sheet was electropolished and then anodized to $200 \mathrm{~V}$ in $0.1 \mathrm{~mol} \mathrm{dm}{ }^{-3}$ ammonium pentaborate electrolyte to develop a relatively smooth surface. The target consisted of a $99.9 \%$ pure titanium disk of $100 \mathrm{~mm}$ diameter and $6 \mathrm{~mm}$ thickness; for the preparation of alloy films, one, two and four square silicon plates, with $15 \mathrm{~mm}$ sides, were placed symmetrically on the region of the target that is sputtered. In order to generate deposited films of uniform composition and thickness, the substrate holders were rotated around the central axis of the chamber as well as their own axes. The compositions of the deposits were examined by RBS and the structures were determined by X-ray diffraction (XRD) using $\mathrm{Cu} \mathrm{K} \alpha$ radiation.

The deposited films were anodized to selected voltages at a constant current density of $50 \mathrm{~A} \mathrm{~m}^{-2}$ in stirred $0.1 \mathrm{~mol} \mathrm{dm}^{-3}$ ammonium pentaborate electrolyte at $293 \mathrm{~K}$ without current decay. A platinum sheet was used as a counter electrode.

Electron transparent sections, $\sim 10 \mathrm{~nm}$ thick, of anodized specimens were obtained by a RMC MT-7 ultramicrotome for TEM observation. Briefly, encapsulated specimens were trimmed initially with glass knives, and then suitably thin sections were obtained with a diamond knife. The sections were examined by JEOL JEM 2000FX transmission electron microscope operated at $200 \mathrm{kV}$. Compositions of the alloy and anodic films were determined by RBS using $2.0 \mathrm{MeV} \mathrm{He}^{2+}$ ions. The scattered particles were detected at $170^{\circ}$ to the incident beam direction, which was normal to the specimen surface. The data were analysed using RUMP program [11]. XPS spectra of the as-deposited specimens were also measured using SHIMADZU ESCA-3200 spectrometer with $\mathrm{Mg} \mathrm{K \alpha}$ excitation $(\mathrm{h} v=1253.6 \mathrm{eV})$. Binding energies of the photoelectrons were calibrated by a method described elsewhere [12].

Dielectric properties of the anodic oxides were examined by an electrochemical 
impedance technique. The impedance and the phase shift were measured in $0.1 \mathrm{~mol} \mathrm{dm}^{-3}$ ammonium pentaborate electrolyte at an open circuit potential with an ac amplitude of $20 \mathrm{mV}$ over a frequency range of $10 \mathrm{mHz}$ to $100 \mathrm{kHz}$.

3. Results

\subsection{XRD patterns}

Figure 1 shows the XRD patterns of the as-deposited titanium and Ti-Si alloys. The pattern of the deposited titanium reveals an hcp structure, with a strong 002 line indicating (001) preferred orientation of the deposit. The pattern of the Ti-6 at $\% \mathrm{Si}$ is similar to that of titanium, but the 002 line shifts slightly to higher angles due to dissolution of silicon in titanium. Further increase in silicon content reduces the diffraction intensity markedly, indicating a less crystalline or amorphous deposit. A halo pattern observed around $20-30^{\circ}$ originates from the glass substrate. Since the equilibrium solubility of silicon in hep titanium is less than 1 at $\%$ [13], the deposited alloys are non-equilibrium, single-phase solid solutions supersaturated with silicon.

\subsection{Voltage-time response}

Voltage-time responses of the titanium and Ti-Si alloys (Fig. 2) reveal an initial voltage surge of about $2 \mathrm{~V}$ at the commencement of anodizing, reflecting the presence of an air-formed film. Subsequently, the formation voltage increases linearly with time. The linear voltage rise continues to voltages less than $20 \mathrm{~V}$ for titanium; thereafter the formation voltage rises at progressively increased rates, followed by a markedly reduced rate of $\sim 1.5 \mathrm{~V} \mathrm{~s}^{-1}$ above $30 \mathrm{~V}$. Evolution of oxygen gas was visible to the naked eye above $30 \mathrm{~V}$. The forming voltage for the Ti- 6 at $\%$ Si alloy rises linearly to $\sim 60 \mathrm{~V}$, with the slope increasing at higher voltages until film breakdown occurs at about $95 \mathrm{~V}$. The change in the slope at lower formation voltage 
compared with that previously reported for the present Ti-6 at\% Si alloy [9] is associated with ageing of the deposited films in laboratory air for more than one month [6]. Ageing induces the development of precursor of crystalline oxide in the air-formed oxide, resulting in the nucleation of crystalline oxide at reduced formation voltages during anodizing. For the Ti-12 at $\% \mathrm{Si}$ and $\mathrm{Ti}-26 \mathrm{at} \% \mathrm{Si}$ alloys, the linear rise of formation voltage continues to the breakdown voltages, which are above $140 \mathrm{~V}$. The slope in the linear growth region increases with the silicon content, from $1.39 \mathrm{~V} \mathrm{~s}^{-1}$ for the Ti-6 at $\% \mathrm{Si}$ alloy to $1.90 \mathrm{~V} \mathrm{~s}^{-1}$ for the Ti-26 at $\% \mathrm{Si}$ alloy.

\subsection{TEM observations}

Transmission electron micrographs of ultramicrotomed sections for the three alloys after anodizing to selected voltages are shown in Figs. 3(a)-(c). The selected area electron diffraction patterns of the respective alloy films are also revealed in the micrographs. The electron diffraction of the Ti-6 at\% Si alloy discloses an hcp structure, while those of the alloys containing 12 and 26 at\% silicon reveal a diffuse ring, typical of amorphous material. These electron diffraction patterns are consistent with the XRD patterns of Fig. 1.

The anodic film formed on the Ti- 6 at $\%$ Si alloy to $75 \mathrm{~V}$, where the rise of formation voltage is no longer linear with anodizing time, is mainly amorphous; however, crystalline regions are evident at a depth of $\sim 40 \%$ of the film thickness. At the region indicated by the arrow, relatively large areas of crystalline oxide are developed with gas bubbles generated around them. As a consequence, the anodic film is slightly thinner than in the surrounding regions. In contrast, the anodic films formed on the alloys with higher silicon contents are totally amorphous, even to a formation voltage of $100 \mathrm{~V}$. The thicknesses of the anodic films are 194 and $150 \mathrm{~nm}$ for the Ti- 6 at\% Si and Ti-26 at\% Si alloys respectively. The films appear to comprise two layers; an inner layer, $68 \%$ of the film thickness, has a light appearance for 
both the alloys. A further increase in contrast difference between the layers is observed for the Ti-26 at $\%$ Si alloy. The light appearance of the inner layer is associated with the presence of silicon species only in the inner layer, as shown by later RBS analyses.

\subsection{Rutherford backscattering spectroscopy}

Figure 4 shows experimental and simulated RBS spectra for the alloy specimens anodized to selected voltages. Simulated spectra, obtained using compositions, thicknesses and densities in Table 1, show good fit to the respective experimental spectra. It is known that boron species are incorporated into the outer part of the anodic film, to a depth of approximately $20 \%$ of the film thickness, on the Ti-Si alloys [9]. In the present RBS analyses of the anodic films, however, the presence of boron species is neglected due to difficulty of detection of such a light element at low concentration. In the spectrum of the anodized Ti-6 at $\% \mathrm{Si}$ alloy, the titanium yield shows a step due to the formation of an anodic film composed mainly of $\mathrm{TiO}_{2}$. A slight depression of the titanium yield before the edge of the alloy/film interface is associated with the presence of silicon species. The depression is more significant for the alloys with increased silicon contents. From comparison of the compositions of the inner layer of the anodic film and the alloy film, shown in Table 1, it is evident that silicon enriches in the inner layer of the anodic film. The charges required to form the anodic films, calculated from the numbers of tetravalent titanium and silicon cations, were similar to those passed during anodizing to selected formation voltages to an accuracy of $5 \%$, indicating that the efficiency of film formation during anodizing is close to $100 \%$.

\subsection{XPS analyses}

XPS spectra of the as-deposited alloy specimens were measured to examine the composition of the air-formed films present before anodizing. Ti $2 p$ spectra of the 
as-deposited specimens, shown in Fig. 5(a), reveals a major peak at $459.1 \mathrm{eV}$, corresponding to $\mathrm{Ti}^{4+}$ species, with a small peak at $453.7 \mathrm{eV}$ for metallic titanium. The Si $2 \mathrm{p}$ spectra, shown in Fig. 5(b), disclose the presence of oxidised silicon species, which appears at $102.3 \mathrm{eV}$. This binding energy corresponds to the tetravalent silicon species. Metallic silicon species appear at $98.5 \mathrm{eV}$. Thus, the air-formed films formed on the Ti-Si alloys contain silicon species, and from the increased intensity of oxidised silicon species with increased silicon content in the alloy, the concentration of silicon species in the air-formed oxide is increased.

\subsection{Dielectric properties}

Since uniform anodic films were grown to relatively high voltages for all the Ti-Si alloys examined, dielectric properties of anodic films were examined by ac impedance spectroscopy. Figure 6 shows Bode plots of the alloy specimens anodized to $50 \mathrm{~V}$. All the alloys revealed a linear voltage to the selected voltage (Fig. 2). The Bode plots indicate dominance of the capacitance of the anodic film in the frequency range from $0.1 \mathrm{~Hz}$ to $1 \mathrm{kHz}$; the impedance changes approximately linearly with frequency, with a slope of -1 and phase shift close to $-90^{\circ}$. Over this frequency range, the impedance increases slightly with increase in silicon content in the alloy, suggesting a reduced capacitance of the anodic film with increased silicon content. At high frequency, above $10 \mathrm{kHz}$, the impedance is nearly constant at $\sim 70 \Omega \mathrm{cm}^{2}$, which corresponds to the resistance of electrolyte.

The decrease of the capacitance of the anodic film formed at $50 \mathrm{~V}$ with the silicon content of the alloy is clearly shown in Fig. 7. Similar to the capacitance, the permittivity of the anodic film decreases with the silicon content. The reduction of the capacitance is less significant than that of permittivity, due to reduced thickness of the anodic film with increased silicon content. Such compositional dependence can be understood from the observation that the permittivities and growth parameters, including field strength and transport numbers of 
cations and anions, of the anodic films formed on the binary alloys are compositional averages of those of films on the respective metals $[10,14,15]$.

\section{Discussion}

\subsection{Crystallisation of anodic oxide}

The present study clearly demonstrates that the amorphous-to-crystalline transition of anodic titanium oxide is hindered by the incorporation of silicon species from substrate. The transition voltage increases with an increase in the silicon content, up to 12 at $\% \mathrm{Si}$. For the alloys containing 12 and 26 at $\%$ silicon, a linear voltage rise continues to dielectric breakdown at $\sim 140 \mathrm{~V}$ (Fig. 2), such that growth of amorphous oxide proceeds until dielectric breakdown. The change in the slope for the Ti- 6 at $\% \mathrm{Si}$ alloy above $\sim 60 \mathrm{~V}$ is associated with the development of crystalline oxide as well as gas generation at the crystalline regions (Fig. 3(a)). The increased ionic resistivity of the crystalline oxide, compared with that of respective amorphous oxide, and generated gas bubbles, which also impede the ionic transport in the anodic oxide under the high electric field, contribute to the increased slope. Indeed, thinner oxide layer is developed where large regions of crystalline oxide and gas bubbles are formed (Fig. 3(a)).

The crystalline oxide developed in the anodic film on the Ti- 6 at $\% \mathrm{Si}$ alloy is located only at a depth of $\sim 40 \%$ of the film thickness; at a region of increased depth, the oxide is amorphous. Thus, the crystallisation is different from that of anodic oxide on high purity titanium, where the crystalline oxide is nucleated immediately above the metal/film interface. The amorphous anodic oxides formed on various valve metals, including titanium, grow simultaneously by cation egress and anion ingress through a pre-existing air-formed oxide. From the transport numbers of cations in growing anodic films on the Ti-Si alloys, the crystalline oxide appears to be developed at the location of the pre-existing oxide. Thus, it is 
probable that the pre-existing oxide acts as a nucleation site for crystalline oxide. This is supported by previous work, where ageing of a sputter-deposited Ti-6 at\% $\mathrm{Si}$ alloy in laboratory air for a prolonged period reduced the voltage for the amorphous-to-crystalline transition [6]. During ageing, a precursor of crystalline oxide is developed. From the XPS spectra shown in Fig. 5, it is clear that silicon species are incorporated into the air-formed oxide, with the concentration increasing with silicon content of the alloy. Silicon species in the air-formed oxide modify the structure of the air-formed oxide, suppressing the development of the precursor of the crystalline oxide, particularly when the concentration is sufficiently high. Thus, anodic films free from crystalline oxides are formed on the Ti-12 at $\%$ Si and Ti-26 at\% Si alloys.

\subsection{Transport numbers of cations and anions}

In growing anodic films with an amorphous structure on a range of valve metals, including aluminium[16], niobium[17], tantalum [18-20] and titanium[8, 9], silicon species are known to be immobile. Thus, transport numbers of cations and anions during film growth can be determined from the distribution of silicon species, which act as marker species. In the present anodic films, an outer layer, essentially free from silicon species, is developed at the film/electrolyte interface by egress of titanium ions, while an inner layer containing silicon species is developed at the alloy/film interface by ingress of $\mathrm{O}^{2-} / \mathrm{OH}^{-}$ions. The transport number of cations, $t_{+}$, can be estimated from the following equation,

$$
t_{+}=\frac{\left(N_{T i}\right)_{\text {out }}}{\left(N_{T i}+N_{S i}\right)_{\text {film }}}
$$

in which $N_{\mathrm{Ti}}$ and $N_{\mathrm{Si}}$ are the numbers of respective ions in the outer layer or total anodic film. These values are shwon from RBS analyses. The transport numbers of cations, calculated from this equation, are plotted in Fig. 8 as a function of the composition of the inner layer. In 
the Figure, the apparent field strengths of the inner silicon-containing layer, estimated by assuming a field strength in the outer anodic titanium oxide layer of $0.45 \mathrm{~V} \mathrm{~m}^{-1}$ [4], are also plotted. Despite the marked change in the field strength with the composition of inner layer, the transport number of cations is nearly constant, being 0.42 . The value is consistent with previous reports $[8,9,21]$.

The transport numbers of cations in growing anodic niobium oxide and tantalum oxide are dependent upon current density and temperature of the electrolyte; for anodic tantalum oxide, the value of $t^{+}$increases with increasing current density and decreases with increasing temperature [22]. A similar trend has been reported for anodic niobium oxide [23]. The findings for anodic niobium and tantalum oxides disclose that the transport numbers of cations are influenced by the field strength in the growing anodic oxides, since the current density and temperature of the electrolyte changes the field strength. Interestingly, the present study demonstrates that the change in field strength due to different concentration of incorporated silicon species does not influence the transport number of cations. The different dependence of the transport number of cations on field strength for the present anodic titanium-based oxide and the niobium and tantalum oxides is not yet understood. Further studies are in progress, which examine the influence of current density and temperature on the transport number of cations in thickening anodic oxides on Ti-Si alloys.

\section{Conclusions}

1. An amorphous-to-crystalline transition of anodic titanium oxide is impeded by the incorporation of silicon species from substrate. No transition is evident during anodizing of Ti-Si alloys containing 12 at $\%$ or more silicon before the dielectric breakdown voltage at $\sim 140 \mathrm{~V}$.

2. The crystalline oxide, developed in the anodic film on the Ti-6 at $\% \mathrm{Si}$ alloy, is located at 
the depth of $\sim 40 \%$ of the film thickness. The air-formed oxide present before anodizing acts as a precursor of crystalline oxide.

3. The air-formed oxides on the Ti-Si alloys contain silicon species, with the silicon concentration increasing with the alloy silicon content. The suppression of crystallisation is associated with the modification of the air-formed oxide.

4. The transport number of cations for growing anodic films on the Ti-Si alloys is 0.42 , being independent of silicon content, despite the significant change in the field strength.

Acknowledgments

The present work was supported in part by a Grant-in-Aid for Scientific Research, No. 16360353 from the Japan Society for the Promotion of Science.

References

[1] G.K. Mor, O.K. Varghese, M. Paulose, K. Shankar, C.A. Grimes, Sol. Energy Mater., 90 (2006) 2011.

[2] D. Gong, C.A. Grimes, O.K. Varghese, W.C. Hu, R.S. Singh, Z. Chen, E.C. Dickey, J. Mater. Res., 16 (2001) 3331.

[3] V. Zwilling, M. Aucouturier, E. Darque-Ceretti, Electrochim. Acta, 45 (1999) 921.

[4] A. Aladjem, J. Mater. Sci., 8 (1973) 688.

[5] C.K. Dyer, J.S.L. Leach, J. Electrochem. Soc., 125 (1978) 1032.

[6] H. Habazaki, M. Uozumi, H. Konno, K. Shimizu, P. Skeldon, G.E. Thompson, Corros. Sci., 45 (2003) 2063.

[7] K. Shimizu, G.E. Thompson, G.C. Wood, Thin Solid Films, 77 (1981) 313.

[8] H. Habazaki, K. Shimizu, S. Nagata, P. Skeldon, G.E. Thompson, G.C. Wood, Corros. Sci., 44 (2002) 1047. 
[9] H. Habazaki, K. Shimizu, S. Nagata, P. Skeldon, G.E. Thompson, G.C. Wood, J. Electrochem. Soc., 149 (2002) B70.

[10] H. Habazaki, H. Konno, K. Shimizu, J. Surf. Finish. Soc. Jpn., 54 (2003) 456.

[11] L.R. Doolittle, Nucl. Instr. and Meth., B9 (1985) 344.

[12] K. Asami, J. Electron Spectrosc. Relat. Phenom., 9 (1976) 469.

[13] T.B. Massalski, Binary Alloy Phase Diagrams ed. H. Okamoto. 1990: ASM International.

[14] H. Habazaki, K. Shimizu, P. Skeldon, G.E. Thompson, G.C. Wood, Thin Solid Films, 300 (1997) 131.

[15] H. Habazaki, K. Shimizu, P. Skeldon, G.E. Thompson, G.C. Wood, Proc. R. Soc. Lond. A, 453 (1997) 1593.

[16] G.C. Wood, P. Skeldon, G.E. Thompson, K. Skeldon, J. Electrochem.Soc., 143 (1996) 74.

[17] H. Habazaki, T. Matsuo, H. Konno, K. Shimizu, S. Nagata, K. Matsumoto, K. Takayama, Y. Oda, P. Skeldon, G.E. Thompson, Electrochim. Acta, 48 (2003) 3519.

[18] R.L. Ruth, N. Schwartz, J. Electrochem. Soc., 123 (1976) 1860.

[19] P.J. Silverman, N. Schwartz, J. Electrochem. Soc., 121 (1974) 550.

[20] K. Shimizu, K. Kobayashi, G.E. Thompson, P. Skeldon, G.C. Wood, Philos. Mag. B, 73 (1996) 461.

[21] N. Khalil, J.S.L. Leach, Electrochem. Acta, 31 (1986) 1279.

[22] Q. Lu, P. Skeldon, G.E. Thompson, D. Masheder, H. Habazaki, K. Shimizu, Corros. Sci., 46 (2004) 2817.

[23] S. Ono, M. Baba, M. Shimoyama, H. Asoh, in Surface Oxide Films, 2004, Orlando: The Electrochemical Society. 
Figure captions

Fig. 1 X-ray diffraction patterns of the sputter-deposited Ti and Ti-Si alloys containing 6, 12 and 26 at $\%$ silicon.

Fig. 2 Voltage-time responses of the sputter-deposited Ti and Ti-Si alloys during anodizing at $50 \mathrm{~A} \mathrm{~m}^{-2}$ in $0.1 \mathrm{~mol} \mathrm{dm}^{-3}$ ammonium pentaborate electrolyte at $293 \mathrm{~K}$.

Fig. 3 Transmission electron micrographs of ultramicrotomed sections for the sputter-deposited (a) Ti-6 at $\% \mathrm{Si}$, (b) Ti-12 at $\% \mathrm{Si}$ and (c) Ti-26 at $\%$ Si alloys anodized at $50 \mathrm{~A} \mathrm{~m}^{-2}$ in $0.1 \mathrm{~mol} \mathrm{dm}^{-3}$ ammonium pentaborate electrolyte at $293 \mathrm{~K}$. The formation voltages are $75 \mathrm{~V}$ for Ti- 6 at $\%$ Si alloy and $100 \mathrm{~V}$ for the Ti-12 at $\%$ Si and Ti-26 at\% Si alloys. The selected area electron diffraction patterns of the respective alloys are also shown

Fig. 4 Experimental and simulated RBS spectra of the sputter-deposited (a) Ti-6 at\% Si, (b) Ti-12 at $\% \mathrm{Si}$ and (c) Ti-26 at\% Si alloys anodized at $50 \mathrm{~A} \mathrm{~m}^{-2}$ in $0.1 \mathrm{~mol} \mathrm{dm}^{-3}$ ammonium pentaborate electrolyte at $293 \mathrm{~K}$. The formation voltages are $75 \mathrm{~V}$ for the Ti-6 at $\%$ Si alloy and $100 \mathrm{~V}$ for the Ti-12 at\% Si and Ti-26 at\% Si alloys.

Fig. 5 (a) Ti 2p3/2 and (b) Si 2p XPS spectra of the sputter-deposited Ti-Si alloys containing 6,12 and 26 at $\%$ silicon.

Fig. 6 Bode plots, measured in $0.1 \mathrm{~mol} \mathrm{dm}^{-3}$ ammonium pentaborate, of the anodic films formed to $50 \mathrm{~V}$ on the sputter-deposited Ti-Si alloys containing 6, 12 and 26 at\% silicon in the same electrolyte at $293 \mathrm{~K}$.

Fig. 7 Changes in capacitance and permittivity of the anodic films formed to $50 \mathrm{~V}$ on the sputter-deposited Ti-Si alloys in $0.1 \mathrm{~mol} \mathrm{dm}^{-3}$ ammonium pentaborate at $293 \mathrm{~K}$ as a function of the silicon content in alloy.

Fig. 8 Changes in the apparent field strength and the transport number of cations for the 
anodic films formed to $50 \mathrm{~V}$ on the sputter-deposited Ti-Si alloys in $0.1 \mathrm{~mol} \mathrm{dm}^{-3}$ ammonium pentaborate at $293 \mathrm{~K}$ as a function of the composition of the inner anodic films. 
Table 1 Results of RBS analyses of the sputter-deposited Ti-Si alloys anodized to selected formation voltages at $50 \mathrm{~A} \mathrm{~m}^{-2}$ in $0.1 \mathrm{~mol} \mathrm{dm}^{-3}$ ammonium pentaborate electrolyte at $293 \mathrm{~K}$.

\begin{tabular}{ccclc}
\hline Alloy & $\begin{array}{c}\text { Formation voltage } \\
(\mathrm{V})\end{array}$ & $\begin{array}{c}\text { Thickness } \\
(\mathrm{nm})\end{array}$ & \multicolumn{1}{c}{ Composition } & $\begin{array}{c}\text { Density } \\
\left(\mathrm{Mg} \mathrm{m}^{-3}\right)\end{array}$ \\
\hline \multirow{2}{*}{ Ti-6 at\% Si } & 75 & 65 & $\mathrm{TiO}_{2}$ & 3.8 \\
& & 85 & $\left(\mathrm{Ti}_{0.9} \mathrm{Si}_{0.1}\right) \mathrm{O}_{2}$ & 3.7 \\
Ti-12 at\% Si & 100 & 82 & $\mathrm{TiO}_{2}$ & 3.8 \\
& & 112 & $\left(\mathrm{Ti}_{0.8} \mathrm{Si}_{0.2}\right) \mathrm{O}_{2}$ & 3.6 \\
Ti-26 at\% Si & 100 & 65 & $\mathrm{TiO}_{2}$ & 3.8 \\
& & 85 & $\left(\mathrm{Ti}_{0.55} \mathrm{Si}_{0.45}\right) \mathrm{O}_{2}$ & 3.3 \\
\hline
\end{tabular}




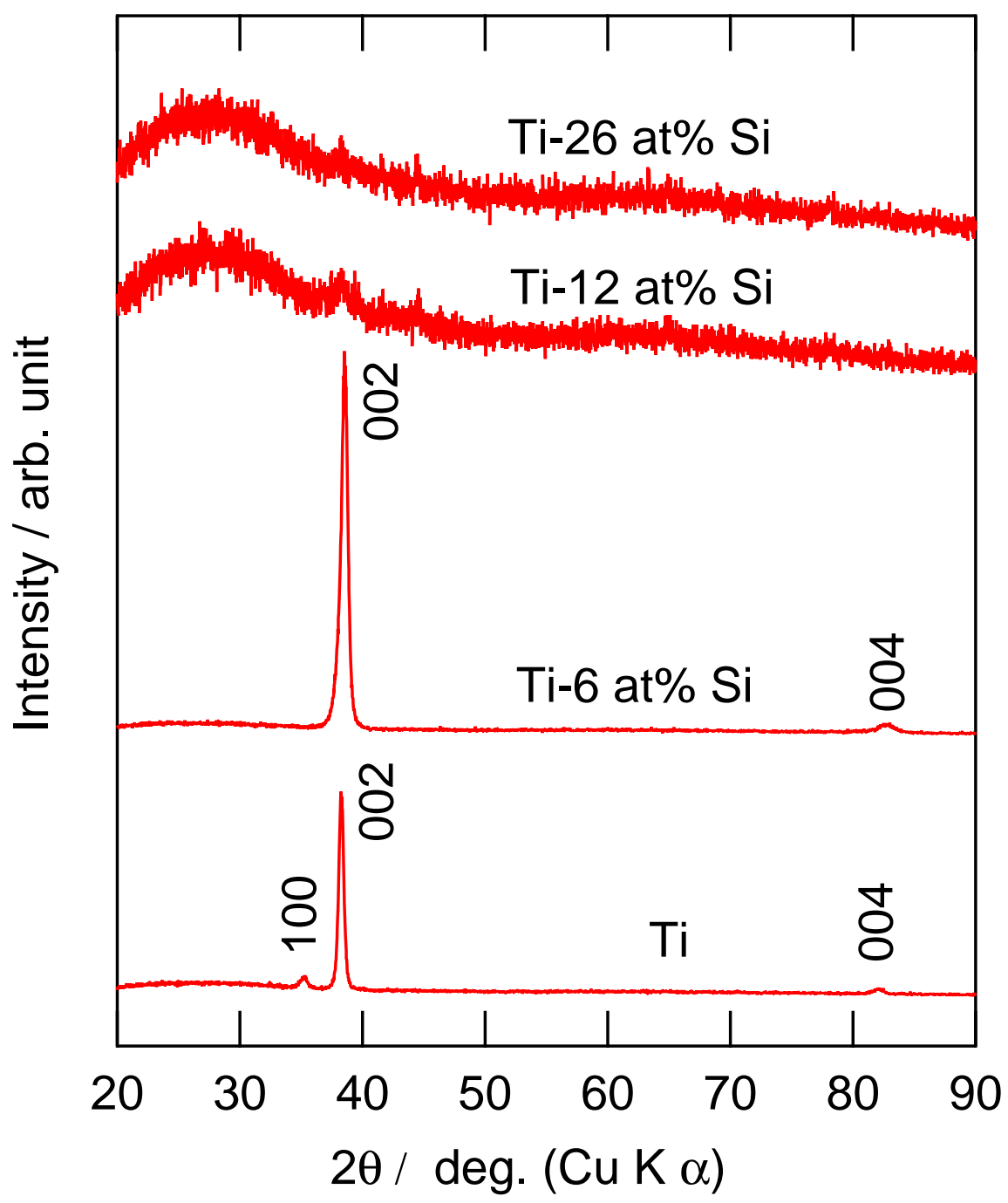




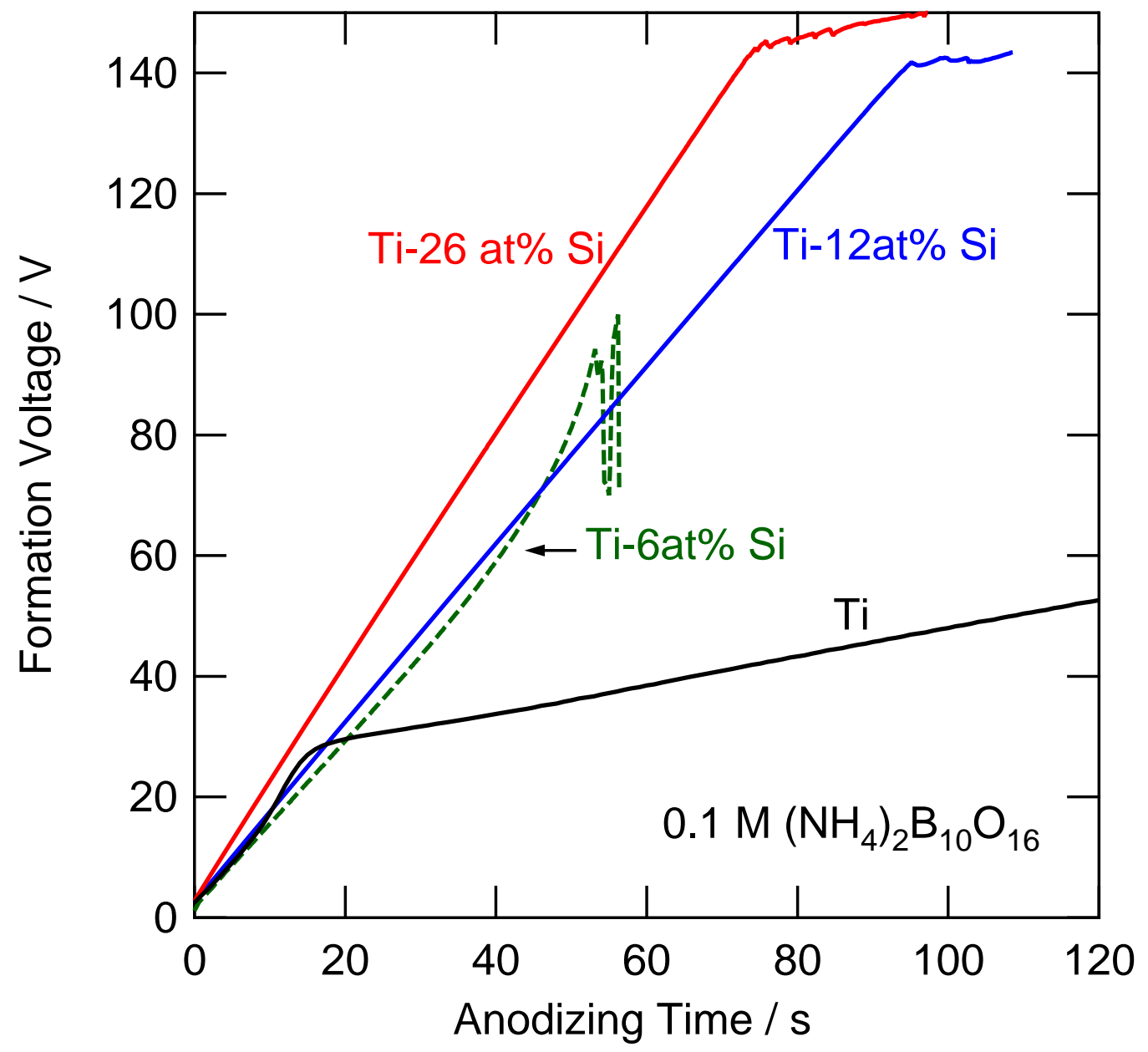


Anodic Film

\section{Ti-6 at\% Si}

(b)

Anodic Film

Ti-12 at\% Si

(c)

Anodic Film 
(a)

Energy / MeV

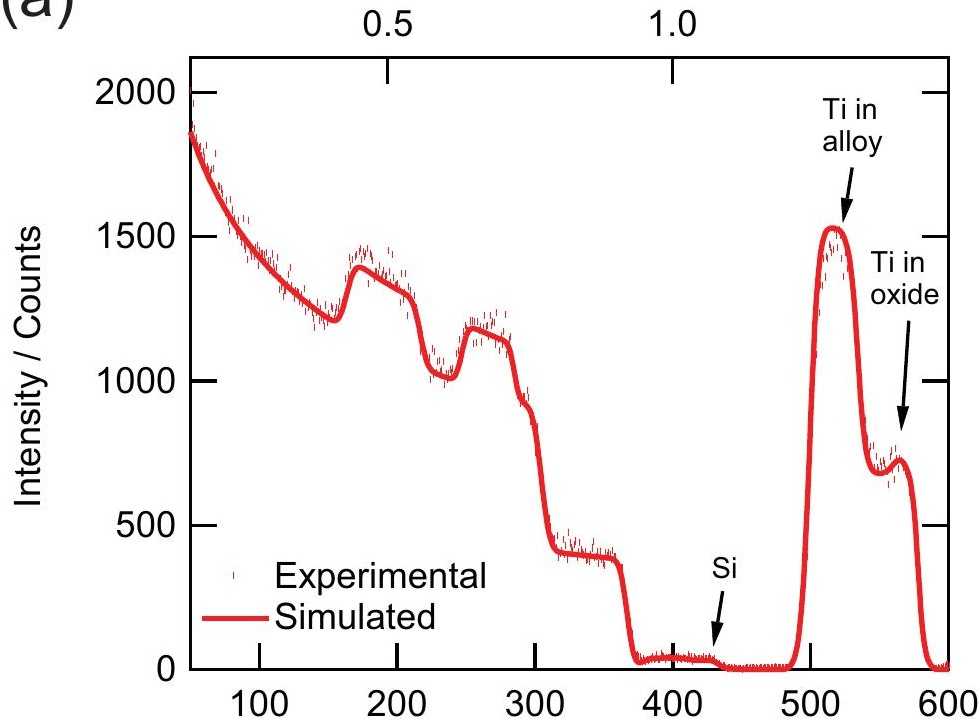

Channel Number

(b)

Energy / MeV

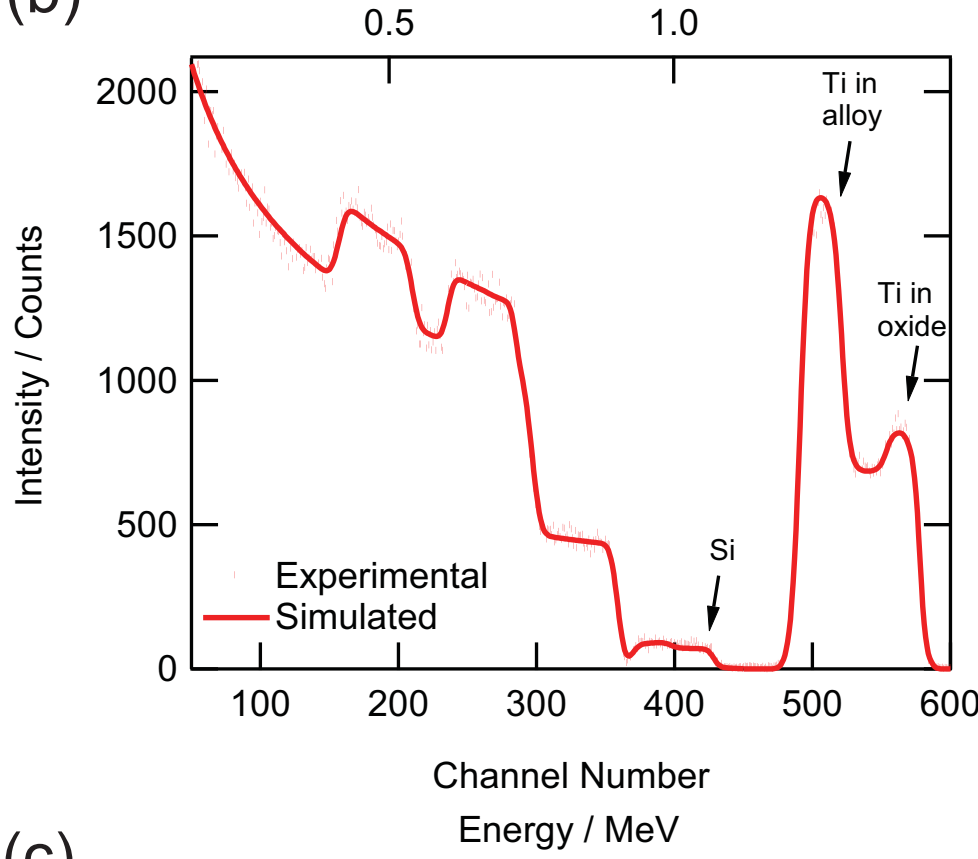

(c)

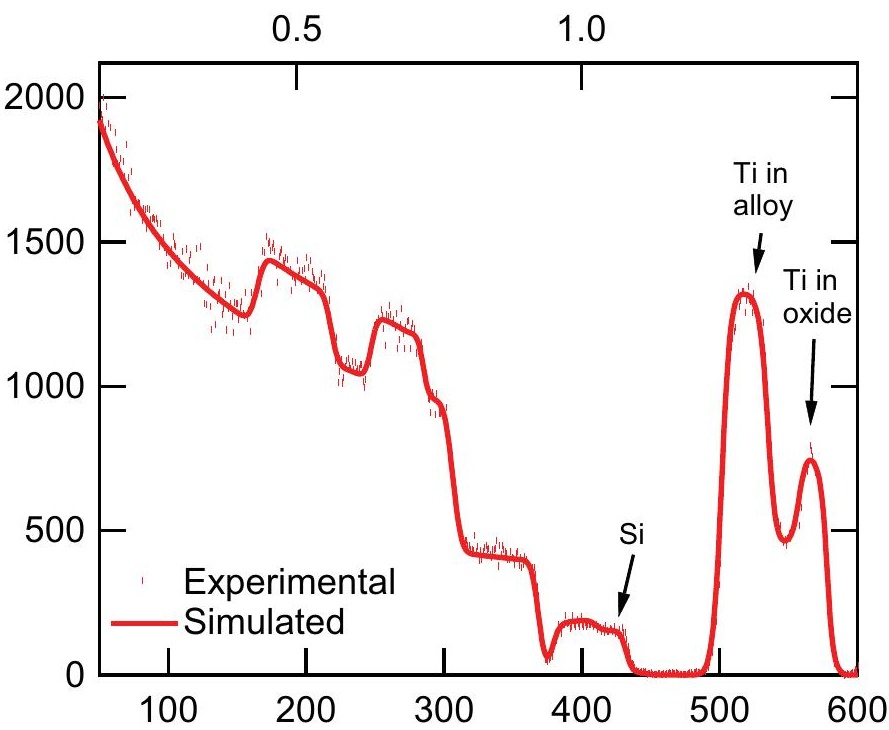

Channel Number 


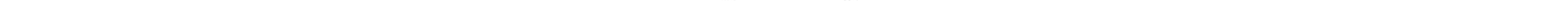




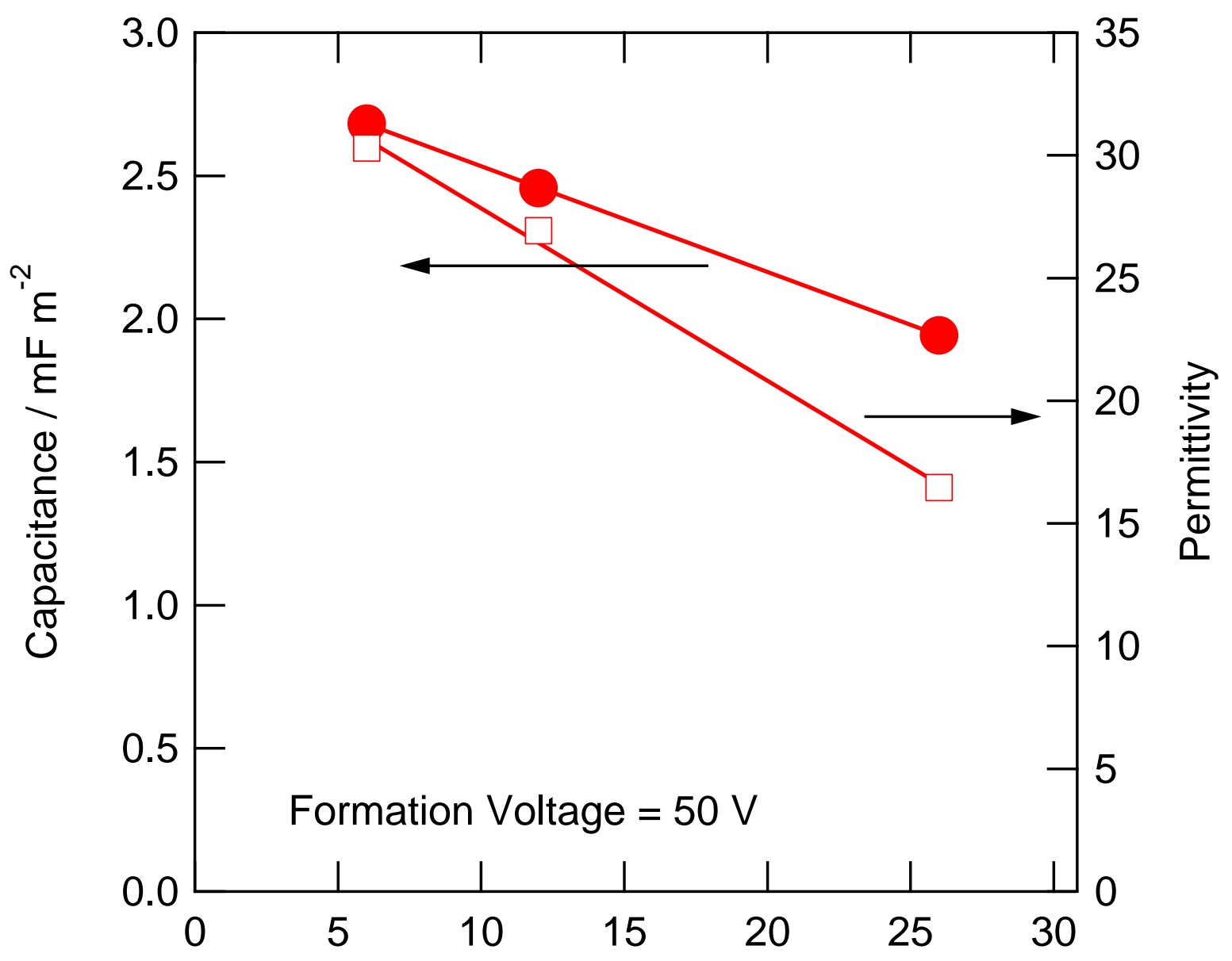

Silicon Content / at\% 
